\title{
Fast Determination of 22 Pesticides in Rice Wine by Dispersive Solid-Phase Extraction in Combination with GC-MS
}

\author{
Nannan Chen ${ }^{1,2}$, Hongbo Gao ${ }^{1}$, Nengsheng $\mathrm{Ye}^{2}$, \\ Qiding Zhong ${ }^{1}$, Zhenghe Xiong ${ }^{*}$, Xuexin $\mathbf{G u}^{2}$ \\ ${ }^{1}$ China National Research Institute of Food and Fermentation Industries, Beijing, China \\ ${ }^{2}$ Department of Chemistry, Capital Normal University, Beijing, China \\ Email: "cnscff@263.net
}

Received November 3, 2011; revised January 6, 2012, accepted January 16, 2012

\begin{abstract}
A rapid method was developed for the determination of 22 pesticides in rice wine. The procedure involved an extraction with acetonitrile and a cleanup step using dispersive solid-phase extraction (d-SPE), and primary-secondary amine (PSA) and octadecylsilane (ODS) were used as sorbents. D-SPE had some advantages over some traditional preparations, especially in time and cost. Both the extraction and cleanup only cost about 15 min per a sample. Then the GC-MS was used for quantitative and qualitative analysis. Matrix-matched standards solution and analyte protectant were compared to decrease the matrix effect, and the former showed a better efficacy. Acceptable linearity was achieved in the range of $0.05-0.30 \mathrm{mg} / \mathrm{L}$. After matrix-matched standards calibration, recoveries were between $60 \%$ and $140 \%$. For the most of pesticides, precision and repeatability were less than $10 \%$ and $16 \%$, respectively. The result indicated that the developed method was suitable for the determination of the multi-pesticides in rice wine.
\end{abstract}

Keywords: d-SPE; Rice Wine; Pesticide; GC-MS; Matrix Effect

\section{Introduction}

Rice wine, beer and wine are considered as the three ancient wines [1]. Rice wine is an alcoholic beverage brewed from rice, and pesticides may be used during the period of rice growth. Rice is directly used for fermentation without any processing, and that causes the presence of pesticide residues in rice wine.

Many reports have been published for the determination of pesticides in alcoholic beverage. Major pretreatments of pesticides in food are liquid-liquid extraction (LLE) [2], solid-phase extraction (SPE) [3-6], and solidphase micro-extraction (SPME) [7,8]. In 2003, dispersive solid-phase extraction (d-SPE) method was introduced for the determination of pesticides by Anastassiades et al. [9], and d-SPE was a simple and rapid technique with high recovery for the determination of pesticides in fruit and vegetables [10]. In previous studies, the combination of several sorbents showed a better cleanup result than using primary-secondary amine (PSA) alone for some complex samples [11-13]. However, few reports were introduced for the determination of the pesticides in rice wine.

In this study, a rapid method was introduced for the

${ }^{*}$ Corresponding author. determination of multi-pesticides in rice wine by GCMS/SIM. Pesticides in rice wine samples were extracted with acetonitrile and cleaned by d-SPE by using the combination of PSA and octadecylsilane (ODS).

\section{Experimental}

\subsection{Reagents and Standards}

Acetonitrile (LC grade) was purchased from Merck (Darmstadt, Germany). PSA and ODS were provided by Bonna-Agela Technologies (Tianjin, China). All the standards of pesticide were obtained from Agricultural Environmental Protection Institution (Tianjin, China), and listed in Table 1. Polyethylene glycol (PEG300) and triphenyl phosphate (TPP) were purchased from SCRC (Beijing, China). Other chemicals were from Beijing Chemical Works (Beijing, China). All of the rice wines and olive oil were purchased from local supermarkets, and the wine samples were kept in a freezer $\left(2^{\circ} \mathrm{C}-4^{\circ} \mathrm{C}\right)$.

\subsection{Instrumentation}

Separations of pesticides were performed on a gas chromatography equipped with a mass detector and an autosampler (GC-MS 2010 plus, Shimadzu, Japan). The ex- 
Table 1. Information of pesticide and IS, retention time $\left(R_{t}\right)$, molecular weight $\left(M_{w}\right)$, quantification and Identification ions.

\begin{tabular}{|c|c|c|c|c|c|c|}
\hline \multirow{2}{*}{ No. } & \multirow{2}{*}{ Pesticides } & \multirow{2}{*}{$\mathrm{R}_{\mathrm{t}}$} & \multirow{2}{*}{$\mathrm{M}_{\mathrm{w}}$} & \multicolumn{3}{|c|}{ Quantification and Identification Ions } \\
\hline & & & & 1 & 2 & 3 \\
\hline 1 & Phorate & 16.15 & 260.38 & 260 & 121 & 231 \\
\hline 2 & $\alpha$-lindane & 16.87 & 290.83 & 219 & 183 & 221 \\
\hline 3 & Diazinon & 17.91 & 304.35 & 304 & 179 & 137 \\
\hline 4 & Pyrimethanil & 18.11 & 199.25 & 198 & 199 & 200 \\
\hline 5 & Heptachlor & 19.21 & 373.35 & 100 & 272 & 237 \\
\hline 6 & Chlorpyrifosmethyl & 20.23 & 322.53 & 286 & 288 & 197 \\
\hline 7 & Chlorothalonil & 21.20 & 265.91 & 266 & 264 & 268 \\
\hline 8 & Metalaxyl & 21.72 & 279.33 & 206 & 249 & 234 \\
\hline 9 & Chlorpyrifos & 21.81 & 350.59 & 314 & 258 & 286 \\
\hline 10 & Methyl-Parathion & 21.96 & 263.21 & 263 & 233 & 246 \\
\hline 11 & Phenthion & 22.48 & 278.33 & 278 & 169 & 153 \\
\hline 12 & Malathion & 22.65 & 330.36 & 173 & 158 & 143 \\
\hline 13 & Parathion & 23.49 & 291.26 & 291 & 186 & 235 \\
\hline 14 & Quinalphos & 24.10 & 298.30 & 146 & 298 & 157 \\
\hline 15 & Isocarbophos & 24.20 & 289.29 & 136 & 230 & 289 \\
\hline 16 & Folpet & 25.07 & 296.66 & 260 & 104 & 297 \\
\hline 17 & Medathion & 25.65 & 302.33 & 145 & 157 & 302 \\
\hline 18 & Triazophos & 29.48 & 313.31 & 161 & 172 & 257 \\
\hline 19 & TPP (IS) & 29.76 & 326.28 & 326 & 325 & 77 \\
\hline 20 & Phosalone & 32.45 & 367.81 & 182 & 367 & 154 \\
\hline 21 & Pyridaben & 33.25 & 364.93 & 147 & 117 & 364 \\
\hline 22 & Fenvalerate & $36.18 ; 36.45$ & 419.90 & 167 & 225 & 419 \\
\hline 23 & Cypermethrin & 38.46 & 416.30 & 181 & 152 & 180 \\
\hline
\end{tabular}

tractant of pesticides were injected with a splitless mode.

DB-1701 capillary column $(30 \mathrm{~m} \times 0.25 \mathrm{~mm} \times 0.25$ $\mu \mathrm{m})$ was provided by Agilent (Palo Alto, CA, USA). Helium was used as carrier gas, and the flow rate was kept at $1.2 \mathrm{~mL} / \mathrm{min}$. The column temperature was maintained at $40^{\circ} \mathrm{C}$ for $1 \mathrm{~min}$, and then ramped at $30^{\circ} \mathrm{C} / \mathrm{min}$ up to $130^{\circ} \mathrm{C}$, then at $5^{\circ} \mathrm{C} / \mathrm{min}$ up to $250^{\circ} \mathrm{C}$, and finally at $20^{\circ} \mathrm{C} / \mathrm{min}$ up to $280^{\circ} \mathrm{C}$. The injector temperature was $280^{\circ} \mathrm{C}$, the volume of injection was $1 \mu \mathrm{L}$. The MS ionization energy was $70 \mathrm{eV}$, the ion-source temperature was $230^{\circ} \mathrm{C}$, and the interface temperature was set at $280^{\circ} \mathrm{C}$. The MS detection was performed in Selection ion mode (SIM), and the characteristic of pesticides are listed in Table 1.

\subsection{Sample Preparation}

TPP (10.00 mg/L, dissolved by acetonitrile) was used as the internal standard (IS) solution, and $100 \mu \mathrm{L}$ IS solution and $2.4 \mathrm{~mL}$ acetonitrile were added into $5.0 \mathrm{~mL}$ rice wine sample, and the mixture was vigorously shaken for 2 min. then $\mathrm{NaCl}(0.50 \mathrm{~g})$ and anhydrous $\mathrm{MgSO}_{4}(2.00 \mathrm{~g})$ were added and then vortexed slightly for $1 \mathrm{~min}$. The extract was then centrifuged for $5 \mathrm{~min}$ at $5000 \mathrm{rpm}$. An aliquot of $1.0 \mathrm{~mL}$ of the upper layer was transferred to a $2.0 \mathrm{~mL}$ micro-centrifuge tube containing $50 \mathrm{mg}$ PSA, 50 $\mathrm{mg}$ ODS and $150 \mathrm{mg} \mathrm{MgSO}_{4}$, shaken for $2 \mathrm{~min}$, and then centrifuged for $4 \mathrm{~min}$ at $8000 \mathrm{rpm}$. Finally, $500 \mu \mathrm{L}$ of extract added $50 \mu \mathrm{L}$ analyte protectant (prepared as it described by $\mathrm{Xu}$ et al. [14]) was placed into an autosampler vial for $\mathrm{GC} / \mathrm{MS}$ analysis.

\section{Results and Discussion}

\subsection{Optimization of d-SPE Procedure}

\subsubsection{Optimization of Sorbents}

PSA, ODS, graphitized carbon black (GCB), and Florisilsilica were used as sorbents in d-SPE procedure $[15,16]$. Among these sorbents, PSA can retain fatty acids and other organic acids, but only slightly reduces the color and vitamin. ODS has a remarkable cleanup ability for non-polar compound, such as some non-polar pigments and vitamins [17]. GCB is a powerful sorbent for pigments, but some pesticides containing benzene ring can be adsorbed by GCB [12]. As shown in Figure 1, peak 


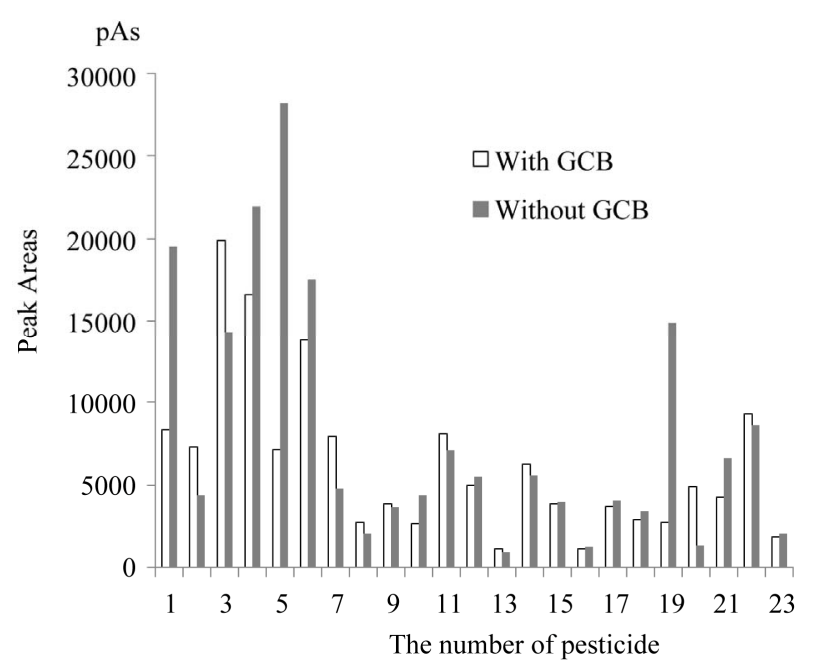

Figure 1. GCB adsorbed some pesticides containing benzene ring. Names of pesticides are listed Table 1.

areas of some pesticides reduced when GCB was used as the sorbent of d-SPE. Due to the light color of rice wine, GCB was not necessary. It is important for the cleanup to select an appropriate material as the sorbent. In previous works, some sorbents such as PSA, ODS, anhydrous $\mathrm{MgSO}_{4}$, and $\mathrm{GCB}$, or their combination was selected for the cleanup of pigments in extracts of wine and grape [18-20]. In this study, the combination of $50 \mathrm{mg}$ PSA, 50 $\mathrm{mg} \mathrm{ODS}$, and $150 \mathrm{mg}$ anhydrous $\mathrm{MgSO}_{4}$ was selected in d-SPE for rice wine extracts cleanup. The SIM chromatogram of pesticide standards and the internal standard was shown in Figure 2.

\subsubsection{Optimization of Temperature and $\mathbf{p H}$}

The low temperature minimizes the degradation of some heat-sensitive pesticides [11]. Rice wine and other reagents were kept in freezer $\left(4^{\circ} \mathrm{C}\right)$ overnight before sample preparation. Keeping the samples in low temperature during the d-SPE procedure was important.

The $\mathrm{pH}$ of samples will be increased when PSA was added and the stability of some alkali-labile pesticides was affected by $\mathrm{pH}$ [18]. Two ways were usually taken to resolve the problem, one was acidifying the extracts quickly to $\mathrm{pH} \sim 5$, and another was the usage of citrate buffer [21]. In this study, rice wine samples were acidity, and the $\mathrm{pH}$ of samples was not obviously increased with the addition of $50 \mathrm{mg}$ PSA.

\subsection{Matrix Effects}

In GC analysis, analyte protectants and matrix-matched calibration solutions were proved to be effective approaches to minimizing matrix effect [22]. The effects of analyte protectants were compared by Xu et al. [14], and the results showed that PEG300 and olive had a better effect. In our study, the combination of PEG300 and olive was used to be the analyte protectant, and the peak

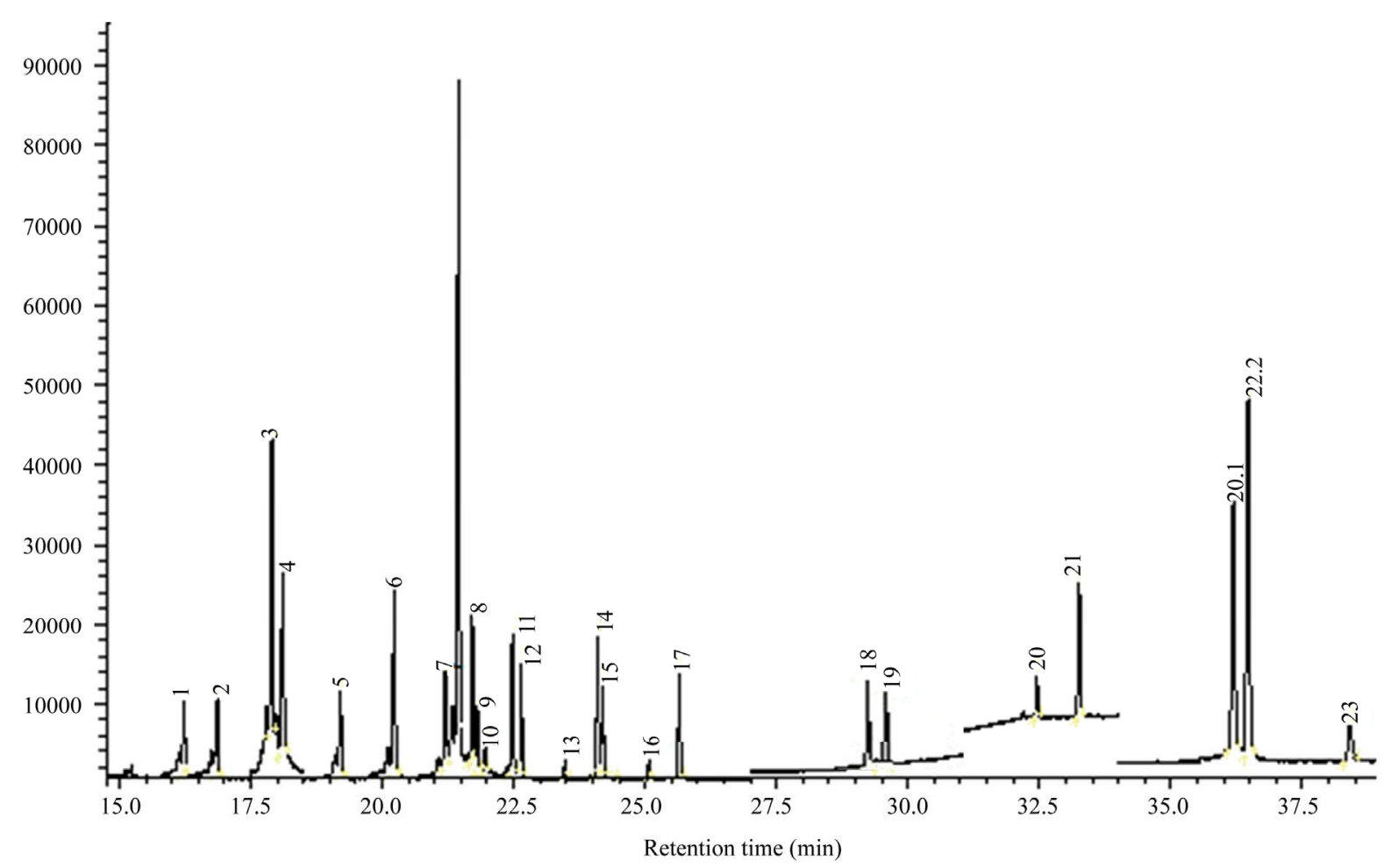

Figure 2. GC-MS/SIM chromatogram of a pesticide standard of $1.0 \mathrm{mg} / \mathrm{L}$ for each pesticide and the internal standard. Names of pesticides are listed Table 1. 
areas of pesticides were compared under the three situations (in pure solvent, matrix-matched calibration solutions and analyte protectant). As shown in Figure 3, both analyte protectant and matrix-matched calibration solution can reduce the matrix effect. The former had a better effect on diazinon, fenvalerate and cypermethrin, but for phorate, pyrimethanil, heptachlor, and chlorpyrifosmethyl, matrix-matched solution was better. In our study the method of matrix-matched calibration solution was selected for the minimizing of matrix effect.

\subsection{Comparison with Other Preparation}

Modern sample preparation techniques should be simple, reliable, cheap, and be similar to common analytical techniques, in order to minimize errors [23]. Information of the major methods used for determining pesticides in alcoholic beverages was presented in Table 2 .

$\mathrm{d}$-SPE had advantages in time and cost, but SPE and some other methods had a better cleanup.

\subsection{Methodology Evaluation}

Linearity was investigated in the range $0.05-0.30 \mathrm{mg} / \mathrm{L}$ with four calibration points, and the correlation coefficients for pesticides were listed in Table 3. Precision was less than $10 \%$, and the recoveries were from $60 \%$ to $140 \%$ at three concentration levels $(0.10,0.20$ and $0.30 \mathrm{mg} / \mathrm{L})$. A SIM chromatography for blank rice wine sample and spiked rice wine was shown in Figure 4. LOQ, LOD, and other information were also listed in Table 3.

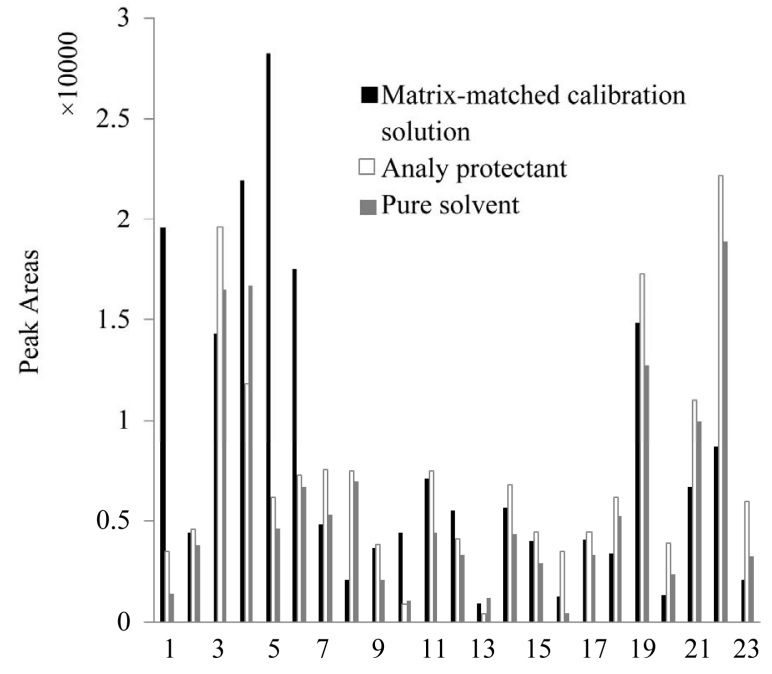

Figure 3. Comparison of pesticide peak areas in pure solvent, matrix-matched standards and adding analyte protectant of mixed PEG and olive oil in optimal concentrations. Names of pesticides are listed Table 1.

\section{Conclusion}

In this work, a rapid method was developed for the determination of multi-pesticides in rice wine by using dSPE-GC-MS. The effect of different adsorbents was investigated, and the combination of different adsorbents was used for the d-SPE procedure with a high results. And then the approaches of minimizing the matrix effect were compared. And the developed method can be used for the determination of pesticides in rice wine samples.

Table 2. Information of some preparations.

\begin{tabular}{|c|c|c|c|c|c|c|c|}
\hline \multirow{2}{*}{ Method } & \multicolumn{7}{|c|}{ Some advantages of preparation } \\
\hline & Rapid & Simple & Low Solvent Volume & Large Pesticide Range & Good Cleanup & Common Instrument & Inexpensive \\
\hline d-SPE & ++ & ++ & + & ++ & + & ++ & ++ \\
\hline SPE & - & - & + & ++ & ++ & ++ & + \\
\hline SPME & ++ & + & ++ & - & ++ & - & - \\
\hline ASE & ++ & + & ++ & + & + & + & ++ \\
\hline USE & - & + & ++ & ++ & + & + & ++ \\
\hline SFE & + & ++ & - & + & + & - & + \\
\hline LPME & ++ & + & ++ & - & ++ & ++ & ++ \\
\hline MSPD & - & + & + & ++ & ++ & ++ & + \\
\hline MISPE & ++ & ++ & + & - & ++ & ++ & + \\
\hline
\end{tabular}

++ very much, + much, - a little; SPE, solid phase extraction; SPME, solid phase microextraction.; ASE, accelerated solvent extraction; USE, ultrasonication extraction, SFE, supercritical fluid extraction; LPME, liquid phase microextraction; MSPD, matrix solid phase dispersion; MISPE , molecularly imprinted solid-phase extraction. 


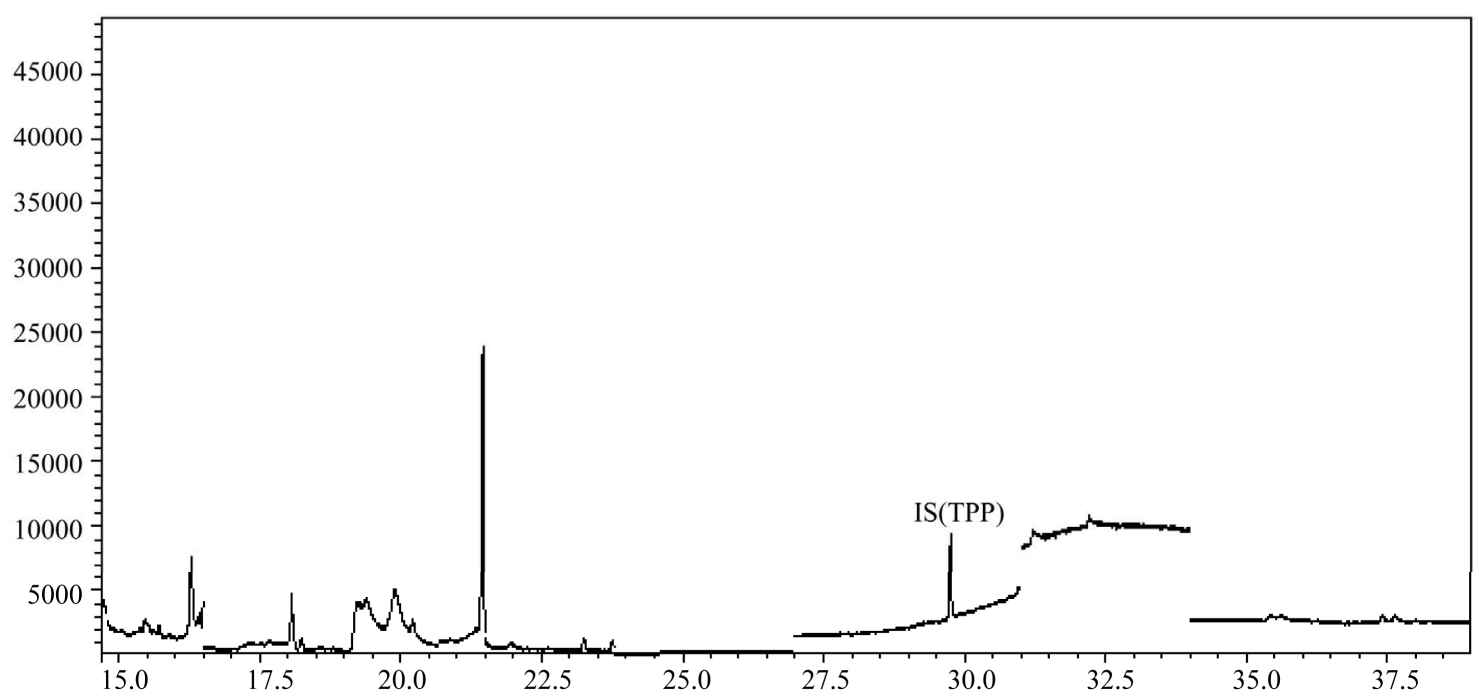

(a)

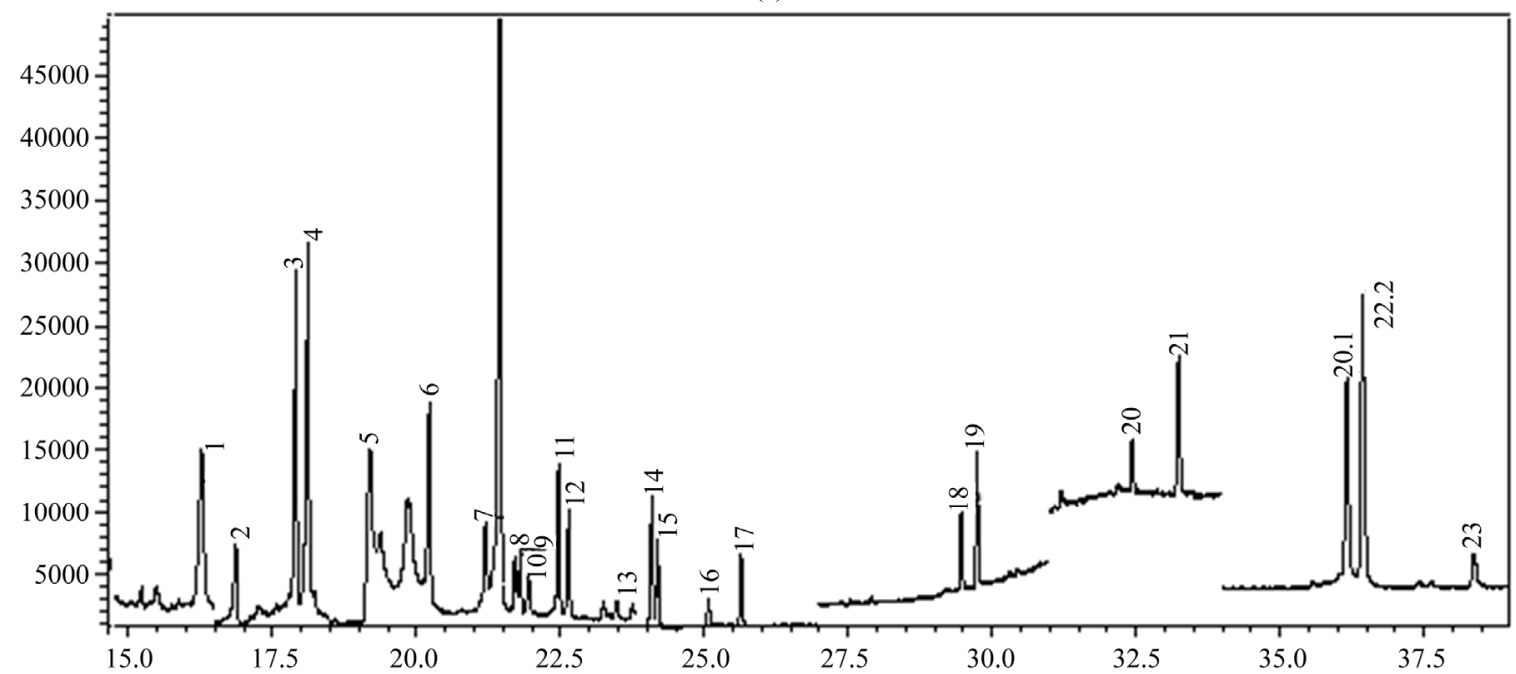

(b)

Figure 4. SIM chromatography for (a) blank rice wine sample; (b) blank rice wine spiked with $0.3 \mathrm{mg} / \mathrm{L}$ of the pesticides. Names of pesticides are on Table 1.

Table 3. Average recovery (\%), precision (\%, RSD), repeatability (\%, RSD), limit of quantitation (LOQ, mg/L), limit of detection (LOD, mg/L) and $\mathrm{R}^{2}$ obtained with the d-SPE method and analyzed by GC/MS. Spiking concentration levels were $0.10,0.20$, and $0.30 \mathrm{mg} / \mathrm{L}$, respectively.

\begin{tabular}{|c|c|c|c|c|c|c|c|c|}
\hline \multirow{2}{*}{ Pesticides } & \multicolumn{3}{|c|}{ Recovery(mg/L) } & \multirow{2}{*}{ Precision (\%) } & \multirow{2}{*}{$\begin{array}{c}\text { Repeatability } \\
(\%)\end{array}$} & \multirow{2}{*}{ LOD } & \multirow{2}{*}{ LOQ } & \multirow{2}{*}{$\mathrm{R}^{2}$} \\
\hline & 0.1 & 0.2 & 0.3 & & & & & \\
\hline Phorate & 106.74 & 98.37 & 113.10 & 7.13 & 15.26 & 0.02 & 0.08 & 0.984 \\
\hline a-lindane & 109.69 & 138.00 & 121.87 & 3.92 & 7.41 & 0.02 & 0.07 & 0.990 \\
\hline Diazinon & 133.56 & 130.69 & 142.36 & 4.48 & 2.52 & 0.01 & 0.02 & 0.997 \\
\hline Heptachlor & 134.77 & 98.37 & 108.16 & 2.81 & 13.78 & 0.02 & 0.06 & 0.978 \\
\hline Chlorpyrifosmethyl & 92.85 & 102.22 & 68.56 & 4.59 & 12.05 & 0.01 & 0.03 & 0.997 \\
\hline Chlorothalonil & 71.80 & 118.80 & 74.82 & 9.93 & 15.27 & 0.02 & 0.06 & 0.988 \\
\hline Metalaxyl & 84.81 & 121.26 & 97.44 & 3.50 & 12.40 & 0.01 & 0.04 & 0.997 \\
\hline Chlorpyrifos & 84.12 & 99.34 & 86.47 & 1.72 & 7.06 & 0.03 & 0.09 & 0.999 \\
\hline
\end{tabular}




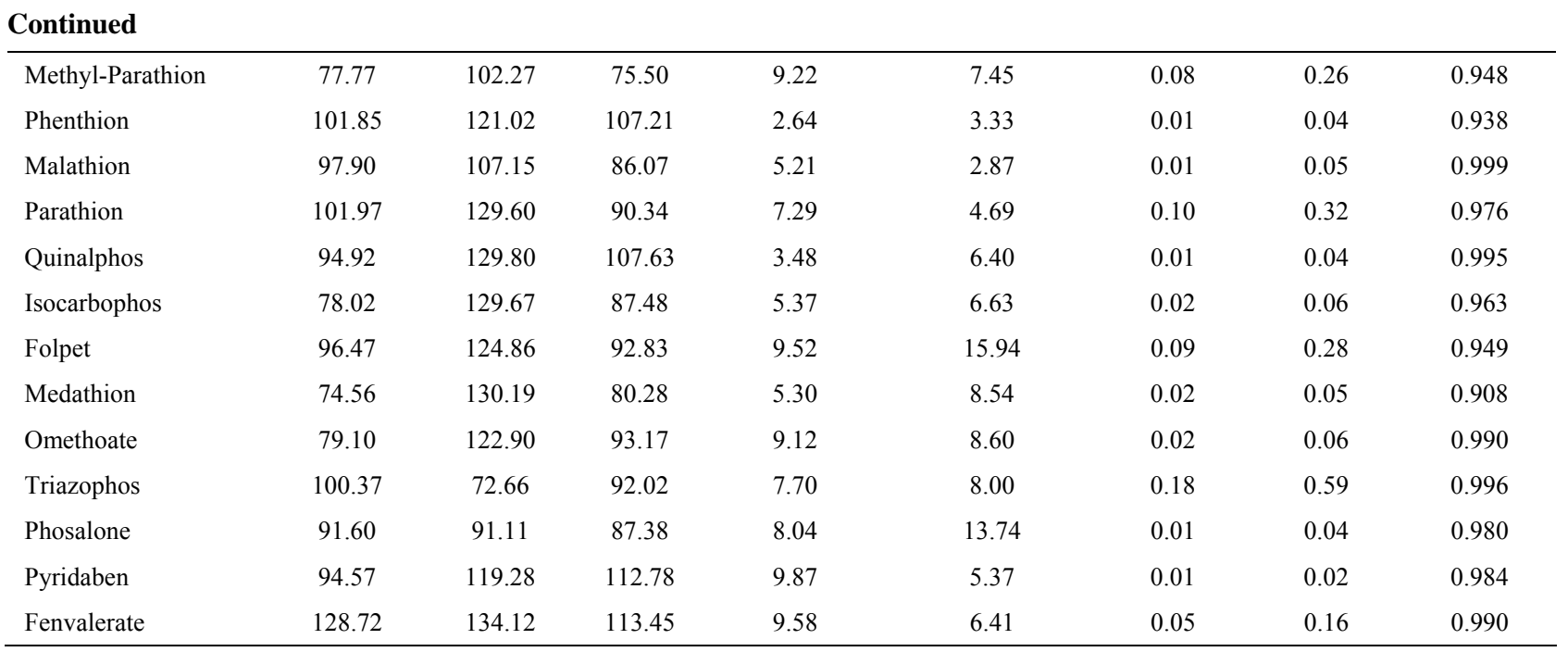

\section{Acknowledgements}

This work was supported by China Spark Program (No. 2010GA700005).

\section{REFERENCES}

[1] H. Yu, Y. Ying, X. Fu and H. Lu, "Quality Determination of Chinese Rice Wine Based on Fourier Transform Near Infrared Spectroscopy," Journal of Near Infrared Spectroscopy, Vol. 14, No. 1, 200, pp. 37-44. doi:10.1255/jnirs. 584

[2] D. T. Likas, N. G. Tsiropoulos and G. E. Miliadis, "Rapid Gas Chromatographic Method for the Determination of Famoxadone, Trifloxystrobin and Fenhexamid Residues in Tomato, Grape and Wine Samples," Journal of Chromatography A, Vol. 1150, No. 1-2, 2007, pp. 208-214. doi:10.1016/j.chroma.2006.08.041

[3] A. Economou, H. Botitsi, S. Antoniou and D. Tsipi, "Determination of Multi-Class Pesticides in Wines by Solidphase Extraction and Liquid Chromatography-Tandem Mass Spectrometry," Journal of Chromatography A, Vol. 1216, No. 31, 2009, pp. 5856-5867. doi:10.1016/i.chroma.2009.06.031

[4] J. J. Jimenez, J. L. Bernal, M. J. Del Nozal, L. Toribio and J. Bernal, "Use of SPE_-GC/EIMS for Residue Analysis in Wine Elaborated from Musts Spiked with Formulations of Chlorpyriphos-Methyl, Methiocarb, Dicofol, and Cyproconazol," Journal of Separation Science, Vol. 30, No. 4, 2007, pp. 547-556. doi: $10.1002 /$ jssc. 200600345

[5] I. Carpinteiro, M. Ramil, I. Rodríguez and R. Cela, "Determination of Fungicides in Wine by Mixed-mode Solid Phase Extraction and Liquid Chromatography Coupled to Tandem Mass Spectrometry," Journal of Chromatography A, Vol. 1217, No. 48, 2010, pp. 7484-7492. doi:10.1016/j.chroma.2010.09.080

[6] G. F. Pang, C. L. Fan, Y. M. Liu, Y. Z. Cao, J. J. Zhang, B. L. Fu, X. M. Li, Z. Y. Li and Y. P. Wu, "Multi-Resi- due Method for the Determination of 450 Pesticide Residues in Honey, Fruit Juice and Wine by Double-Cartridge Solid-Phase Extraction/Gas Chromatography-Mass Spectrometry and Liquid Chromatography-Tandem Mass Spectrometry," Food Additives \& Contaminants: Part A, Vol. 23, No. 8, 2006, pp. 777-810. doi:10.1080/02652030600657997

[7] D. Zhan, R. E. Anli, N. Vural and M. Bayram, "Determination of Chloroanisoles and Chlorophenols in Cork and Wine by Using HS-SPME and GC-ECD Detection," Journal of the Institute of Brewing, Vol. 115, No. 1, 2009, pp. 71-77.

[8] L. M. Ravelo-Pérez, J. Hernández-Borges, T. M. BorgesMiquel and Má Rodríguez-Delgado, "Solid-Phase Microextraction and Sample Stacking Micellar Electrokinetic Chromatography for the Analysis of Pesticide Residues in Red Wines," Food Chemistry, Vol. 111, No. 3, 2008, pp. 764-770. doi:10.1016/j.foodchem.2008.04.020

[9] M. Anastassiades, S. J. Lehotay, D. Tajnbaher and F. J. Schenck, "Fast and Easy Multiresidue Method Employing Acetonitrile Extraction/Partitioning and 'Dispersive SolidPhase Extraction' for the Determination of Pesticide Residues in Produce," Journal of AOAC International, Vol. 86, No. 2, 2003, pp. 412-431.

[10] J. Dong, X. M. Gong, L. Zhang and H. T. Wang, "Determination of Imidacloprid, Tebufenozide, Avennectins and Hexythiazox in Vegetables by QuEChERS-HPLC," Chinese Journal of Analysis Laboratory, Vol. 3, 2008, pp. 91-94.

[11] S. H. Patil, K. Banerjee, S. Dasgupta, D. P. Oulkar, S. B. Patil, M. R. Jadhav, R. H. Savant, P. G. Adsule and M. B. Deshmukh, "Multiresidue Analysis of 83 Pesticides and 12 Dioxin-Like Polychlorinated Biphenyls in Wine by Gas Chromatography-Time-of-Flight Mass Spectrometry," Journal of Chromatography A, Vol. 1216, No. 12, 2009, pp. 2307-2319. doi:10.1016/j.chroma.2009.01.091

[12] K. Zhang, J. W. Wong, D. G. Hayward, P. Sheladia, A. J. Krynitsky, F. J. Schenck, M. G. Webster, J. A. Ammann and S. E. Ebeler, "Multiresidue Pesticide Analysis of 
Wines by Dispersive Solid-Phase Extraction and Ultrahigh-Performance Liquid Chromatography-Tandem Mass Spectrometry," Journal of Agricultural and Food Chemistry, Vol. 57, No. 10, 2009, pp. 4019-4029. doi:10.1021/if9000023

[13] S. C. Cunha, J. O. Fernandes, A. Alves and M. Oliveira, "Fast Low-pressure Gas Chromatography-Mass Spectrometry Method for the Determination of Multiple Pesticides in Grapes, Musts and Wines," Journal of Chromatography A, Vol. 1216, No. 1, 2009, pp. 119-126. doi:10.1016/j.chroma.2008.11.015

[14] X. Xu, L. Li, W. Zhong and Y. He, "Rapid GC-MS Analysis of Pesticide Residues Using Analyte Protectants," Analytical Letters, Vol. 42, No. 16, 2009, pp. 2578-2591. doi:10.1080/00032710903243646

[15] J. M. Lee, J. W. Park, G. C. Jang and K. J. Hwang, "Comparative Study of Pesticide Multi-Residue Extraction in Tobacco for Gas Chromatography-Triple Quadrupole Mass Spectrometry," Journal of Chromatography A, Vol. 1187 , No. 1,2008 , pp. 25-33. doi:10.1016/j.chroma.2008.02.035

[16] Y. Jiang, X. Li, J. Xu, C. Pan, J. Zhang and W. Niu, "Multiresidue Method for the Determination of 77 Pesticides in Wine Using QuEChERS Sample Preparation and Gas Chromatography with Mass Spectrometry," Food Additives \& Contaminants: Part A, Vol. 26, No. 6, 2009, pp. 859-866. doi:10.1080/02652030902822794

[17] W. Shen, K. Yu, Q. Gui, Y. Jiang, Z. Zhao, C. Shen, B. $\mathrm{Wu}$ and $\mathrm{X}$. Chu, "Determination of 107 Pesticide Residues in Vegetables Using Off-Line Dispersive Solidphase Extraction and Gas Chromatography-tandem Mass Spectrometry," Chinese Journal of Chromatography, Vol. 4, 2009, pp. 391-400.

[18] P. Payá, M. Anastassiades, D. Mack, I. Sigalova, B. Tasdelen, J. Oliva and A. Barba, "Analysis of Pesticide Re- sidues Using the Quick Easy Cheap Effective Rugged and Safe (QuEChERS) Pesticide Multiresidue Method in Combination with Gas and Liquid Chromatography and Tandem Mass Spectrometric Detection," Analytical and Bioanalytical Chemistry, Vol. 389, No. 6, 2007, pp. $1697-$ 1714. doi:10.1007/s00216-007-1610-7

[19] C. Lesueur, P. Knittl, M. Gartner, A. Mentler and M. Fuerhacker, "Analysis of 140 Pesticides from Conventional Farming Foodstuff Samples after Extraction with the Modified QuECheRS Method," Food Control, Vol. 19, No. 9, 2008, pp. 906-914. doi:10.1016/j.foodcont.2007.09.002

[20] T. D. Nguyen, J. E. Yu, D. M. Lee and G. H. Lee, “A Multiresidue Method for the Determination of 107 Pesticides in Cabbage and Radish Using QuEChERS Sample Preparation Method and Gas Chromatography Mass Spectrometry," Food Chemistry, Vol. 110, No. 1, 2008, pp. 207-213. doi:10.1016/j.foodchem.2008.01.036

[21] A. Garrido Frenich, J. L. Martínez Vidal, E. PastorMontoro and R. Romero-González, "High-Throughput Determination of Pesticide Residues in Food Commodities by Use of Ultra-performance Liquid Chromatography -Tandem Mass Spectrometry," Analytical and Bioanalytical Chemistry, Vol. 390, No. 3, 2008, pp. 947-959. doi:10.1007/s00216-007-1746-5

[22] K. Maštovská, S. J. Lehotay and M. Anastassiades, “Combination of Analyte Protectants to Overcome Matrix Effects in Routine GC Analysis of Pesticide Residues in Food Matrixes," Analytical Chemistry, Vol. 77, No. 24, 2005, pp. 8129-8137. doi:10.1021/ac0515576

[23] A. Beyer and M. Biziuk, "Applications of Sample Preparation Techniques in the Analysis of Pesticides and PCBs in Food," Food Chemistry, Vol. 108, 2008, pp. 669-680. doi:10.1016/j.foodchem.2007.11.024 